\title{
The role of collagen crosslinks in ageing and diabetes - the good, the bad, and the ugly
}

\author{
Jess G. Snedeker ${ }^{1}$ \\ Alfonso Gautieri ${ }^{2}$ \\ 1 University Hospital Belgrist, University of Zürich, \\ Switzerland \\ 2 Institute for Biomechanics, ETH Zürich, Switzerland
}

Corresponding author:

Jess G. Snedeker

Institute for Biomechanics, ETH Zürich

Forchstrasse 340

8008 Zürich, Switzerland

E-mail: snedeker@ethz.ch

\section{Summary}

The non-enzymatic reaction of proteins with glucose (glycation) is a topic of rapidly growing importance in human health and medicine. There is increasing evidence that this reaction plays a central role in ageing and disease of connective tissues. Of particular interest are changes in typeI collagens, long-lived proteins that form the mechanical backbone of connective tissues in nearly every human organ. Despite considerable correlative evidence relating extracellular matrix (ECM) glycation to disease, little is known of how ECM modification by glucose impacts matrix mechanics and damage, cell-matrix interactions, and matrix turnover during aging. More daunting is to understand how these factors interact to cumulatively affect local repair of matrix damage, progression of tissue disease, or systemic health and longevity. This focused review will summarize what is currently known regarding collagen glycation as a potential driver of connective tissue disease. We concentrate attention on tendon as an affected connective tissue with large clinical relevance, and as a tissue that can serve as a useful model tissue for investigation into glycation as a potentially critical player in tissue fibrosis related to ageing and diabetes.

KEY WORDS: collagen, advanced glycation endproducts, crosslinks, tendon mechanics, diabetes, ageing.
Setting the stage: central functional roles of collagen

The term collagen comes from the Greek word $\kappa о \lambda \lambda \alpha$ (kolla, meaning "glue"), due to the use of animal skin and collagen-rich tissues a glue source ${ }^{1}$. In a broader sense, collagen is in fact the "glue" of our body, holding it together by providing elasticity and strength to most tissues where mechanical function is essential, such as skin, cartilage, tendons and bones ${ }^{2,3}$.

The collagen family of proteins is the most abundant in the human body - representing a basic building block within nearly every tissue and organ. Collagen structures form largely by cell-mediated self-assembly of small collagen molecules (300 nm in length; circumscribable with an approximate $1.5 \mathrm{~nm}$ diameter $)^{4}$. During the process of collagen self-assembly, various types of inter-molecular crosslinks stabilize the helical supramolecular structures that form. Collagen crosslinks can be conceptually classed as either enzymatic or non-enzymatic, with enzymatic crosslinking representing an essential step in the development and repair of collagen connective tissues. Whether in the early stages of embryonic tendon development or the late stages of connective tissue disease, collagen crosslinks play a key role in tissue mechanics, cell signaling, matrix damage accumulation, and tissue repair.

Cell-matrix interactions involving collagen include a wide range of classical receptor-ligand mediated signaling pathways ${ }^{5}$. Nonetheless the main functional feature of most collagens (this review will focus on type-I collagen) is mechanical load bearing of tensile force. The mechanical function of any connective tissue results from often highly sophisticated architectural arrangement of collagen substructures, along with other elastic extracellular matrix proteins such as elastin, and water binding proteoglycans. Although soft connective tissues of the body are composed of nearly identical basic molecular building blocks, their varied arrangement makes possible an exquisite range of potential tissue mechanical properties. The cells that mediate the functional assembly of these building blocks do so according to their epigenetic pre-program as guided by the mechanical demands on the tissue.

Within any collagenous connective tissue, the functional building blocks that provide tensile strength and elasticity are called collagen "fibrils". The collagen fibril is a helically arranged supramolecular structure that can range in diameter from a few to several hundred nanometers, with lengths that can run on the or- 
der of centimeters ${ }^{6}$. How collagen molecules are accrued into these structures (a process known as fibrillogenesis) relies on sequences of elegant intracellular and extracellular events that, while fascinating, are outside the scope of the present review. Current evidence suggests that the mature collagen fibrils resulting from fibrillogenesis are highly elastic structures - meaning that they mechanically load and unload in a mostly reversible fashion. To be able to reversibly load and unload, without damage, is the defining functional requirement of these protein superstructures. Collagen cross linking is a central enabler (and potential disabler) of this function.

\section{The good: enzyme mediated collagen cros-slinking}

The mechanical competence of individual type-I collagen fibrils heavily depends on the enzyme lysyl oxidase, which regulates the robust formation of stable inter-molecular collagen crosslinks during maturation $^{7}$. The absence of these head to tail chemical bonds drastically diminishes collagen fibril strength and whole tissue function ${ }^{8,9}$. Lysyl oxidase specifically acts on lysine or hydroxylysine in the telopeptide region of the collagen molecule, and results in a divalent, immature crosslink with an opposing aminoacid in the triple-helical region ${ }^{10}$. These immature crosslinks later spontaneously convert into more stable trivalent crosslinks that increase collagen interconnectivity, fibril stability and whole tendon mechanical integrity (for excellent reviews) ${ }^{7,11}$.

Simple biochemical correlations of native crosslink content with tendon mechanical properties are rather weak $^{12-15}$, reflecting the likely confounding influence of other dominant structural or compositional factors ${ }^{16}$. The essential functional role of crosslinking in collagen fibril stability and whole tissue integrity, however, is clearly demonstrated in the severely compromised connective tissues of animals subjected to dietary inhibition of lysyl oxidase, which results in collagen fibrils and tendons with reduced strength ${ }^{8,9}$. The importance of crosslinks to fibril integrity has been indicated theoretically ${ }^{17}$ and demonstrated experimentally ${ }^{9,18}$ by balancing molecular slip and stretch under load.

The importance of crosslinking in preventing molecular slippage and resultant fibrillar damage can also be inferred from the decreased thermal stability of tendons that is known to take place after sub-maximal tissue overload ${ }^{19}$. Given that lysyl oxidase mediated crosslinks are so essential to the proper development of fibril structure and mechanical integrity, these are perhaps the best-characterized collagen crosslinkers.

The bad: advanced glycation endproduct crosslinking

While enzyme driven crosslinking plateaus at maturation, connective tissue stiffness has been shown to further increase with age and diabetes $20-26$. This tissue stiffening has been associated with non-enzymatic, oxidative reactions between glucose and collagen which lead to the formation of so-called advanced glycation end-products (AGEs) ${ }^{27,28}$. AGE accumulation is particularly high in long-lived proteins, such as collagen. Indeed, collagen half-life varies between tissues but remains generally large, from 1-2 years for bone collagen to about 10 years for type I in skin ${ }^{29}$. The low biological turnover of collagen makes it therefore susceptible to interaction with metabolites, primarily glucose. Aside from protein longevity, another factor that influences the formation of AGEs is the glucose level in the blood stream. Hyperglycemia related to diabetes is suspected to strongly predispose tissues of these patients to accumulation of $\mathrm{AGEs}^{30,31}$.

The glycation reaction initiates with the formation of a reversible Schiff base between a carbohydrate - typically glucose - and a protein amino group (e.g., a collagen lysine side-chain) (Fig. 1). The unstable Schiff base becomes a stable intermediate keto amine, often designated asa so-called Amadori product. Afterwards, a complex series of reactions (over the course of months or years) lead to various meta-

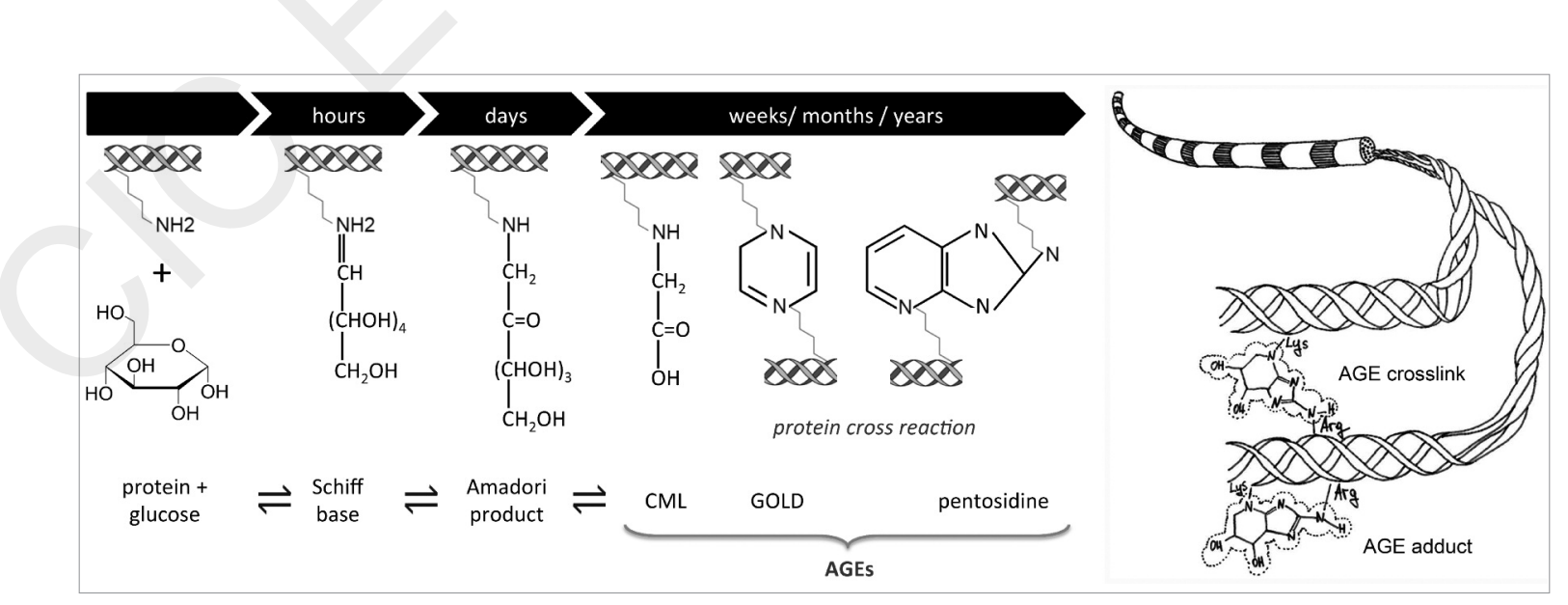

Figure 1. (Left) Schematic of the sequence of metabolic chemical reactions behind AGE formation (e.g. pentosidine) ${ }^{72}$ and (Right) how such products may form adducts and/or crosslinks on collagen structures ${ }^{39}$. 
bolic by-products of glycolysis including the products glyoxal, methyl glyoxal (MGO) and 3-deoxyglucosone, all of which can interact with extracellular proteins to form $\mathrm{AGEs}^{32}$. Some AGEs can bridge between the free amino groups of neigh boring proteins to form inter-molecular crosslinks, while others known as 'adducts' affect only a single protein ${ }^{33}$. Among the different AGEs, the most abundant in collagen tissues has been recently found to be glucosepane, a lysinearginine crosslink ${ }^{34,35}$.

So far, there is no direct experimental evidence linking AGEs with increases in collagen fibril stiffness, which in turn would cause increased stiffness at higher levels of tissue architecture. Although the mechanical effects of AGEs at the molecular and supramolecular levels are poorly understood, this link seems plausible and has been widely presumed to exist on the basis of the well documented correlation between AGE markers (pentosidine; auto-fluorescence) and increasing tissue stiffness ${ }^{36}$.

\section{The ugly: functional consequences of AGEs in con- nective tissue}

Despite the recognized importance of AGEs in the development of age - and diabetes - related conditions, there are still several important open questions regarding their role in the onset and progression of connective tissue disease. These can be broadly divided into two functional classes, biological and biomechanical.

The biological aspect relates primarily to collagenprotein and collagen-cell interactions. Here, the formation of AGEs (adducts or crosslinks) on specific amino acids involved in intermolecular recognition could lead to the dramatic modification of the interaction of collagen with other molecules such as proteoglycans (PGs), enzymes (e.g., collagenase) and cell integrins. AGEs modify the collagen surface and are known to affect cell-matrix interactions in a manner leading to inhibited wound repair and exacerbated inflammation 37,38 . A recent modeling study 39 based on atomistic model of collagen 40 has shown that collagen amino acids that are most likely prone to form glucosepane crosslinks (due to their position and configuration) are found close to collagenase and cell integrin binding sites, as well as near interaction domain for heparin and keratansulphate. These findings resonate with experimental investigations showing that collagen glycation induces a reduced affinity for heparin and keratansulphate proteoglycans (but not for dermatansulphate and decorin) as well as reduced endothelial cell migration ${ }^{41}$. Protein glycation ultimately stimulate cellular production of reactive oxygen species, and the activation of inflammatory signaling cascades via AGE signaling receptors (RAGEs) ${ }^{42}$.

On the other hand, nonenzymatic intermolecular crosslinking are believed to alter the biomechanics of collagenous tissue. Glucose reaction with the amino acid side-chains, and subsequent further reaction to form a crosslink with an adjacent collagen molecule, results in a modification of the physical properties of the collagen, but the detailed effects of AGEs on collagen mechanics at the different hierarchical scales are still poorly understood. While these intermolecular crosslinks have been tied to higher failure loads, stiffness, and denaturation temperatures ${ }^{30,43}$, they are also associated with increased mechanical fragility of the tissue ${ }^{44}$. AGE crosslinks have also been implicated in reduced remodeling capacity, a concept that has been demonstrated in vitro as reduced sensitivity to collagenase $43,45,46$.

How collagen crosslinks affect whole tendon function is complex, as indicated by an increased failure load of individual collagen fibers that paradoxically yields diminished tissue failure properties. The picture is further muddied by contradictory reports in the literature that have inconsistently correlated crosslink density to tissue stiffness ${ }^{13,44,47-52}$. In an attempt to eliminate potentially confounding effects of genotype, systemic alterations due to age or disease state, and lifestyle, some studies have investigated the effects of crosslinking by direct incubation of tendon with a range of sugars and/or aldehydes solutions, serving as valuable models for ageing and diabetes (Fig. 2). These studies have generally well-mimicked the structural changes of collagen fibrils that have been found in vivo, but these studies clearly associate AGE crosslinks to tissue stiffening and brittleness $46,53,54$. Such changes are potentially critical, since altered extracellular matrix mechanics will subsequently affect the mechanical stimuli that drive resident cell behavior and regulate cellular repair of matrix damage. It is more than feasible that age-related mechanical changes in the collagen matrix could thus play a role in loss of tissue homeostasis and ability to cope with the micro-damage that accumulates in everyday life li,28. $^{27}$.

Clinical experience suggests that aged and diabetic connective tissues appear stiffer to the touch than healthy tissues, although changes in stiffness cannot be explained by increased collagen content alone ${ }^{22,25}$. Aged and diabetic tissues are also accompanied by characteristic yellowing of the collagen matrix that accords with experimental evidence indicating age-related decreases in collagen solubility and heightened collagen resistance to protease breakdown. These phenomena have been causally linked to non-enzymatic glycation of proteins ${ }^{55-58}$.

\section{The final duel: toward AGE crosslink breaking thera- pies}

Various approaches have been taken to prevent formation of AGEs (for an excellent review) ${ }^{59}$. For instance, a reduced alimentary glucose uptake has been shown to be beneficial, as have approaches seeking to breakdown or block intermediate molecular interactions. Further efforts have shown potential benefit in "protecting" amino acid residues by agents that competitively bind aldehydes. Complementing 

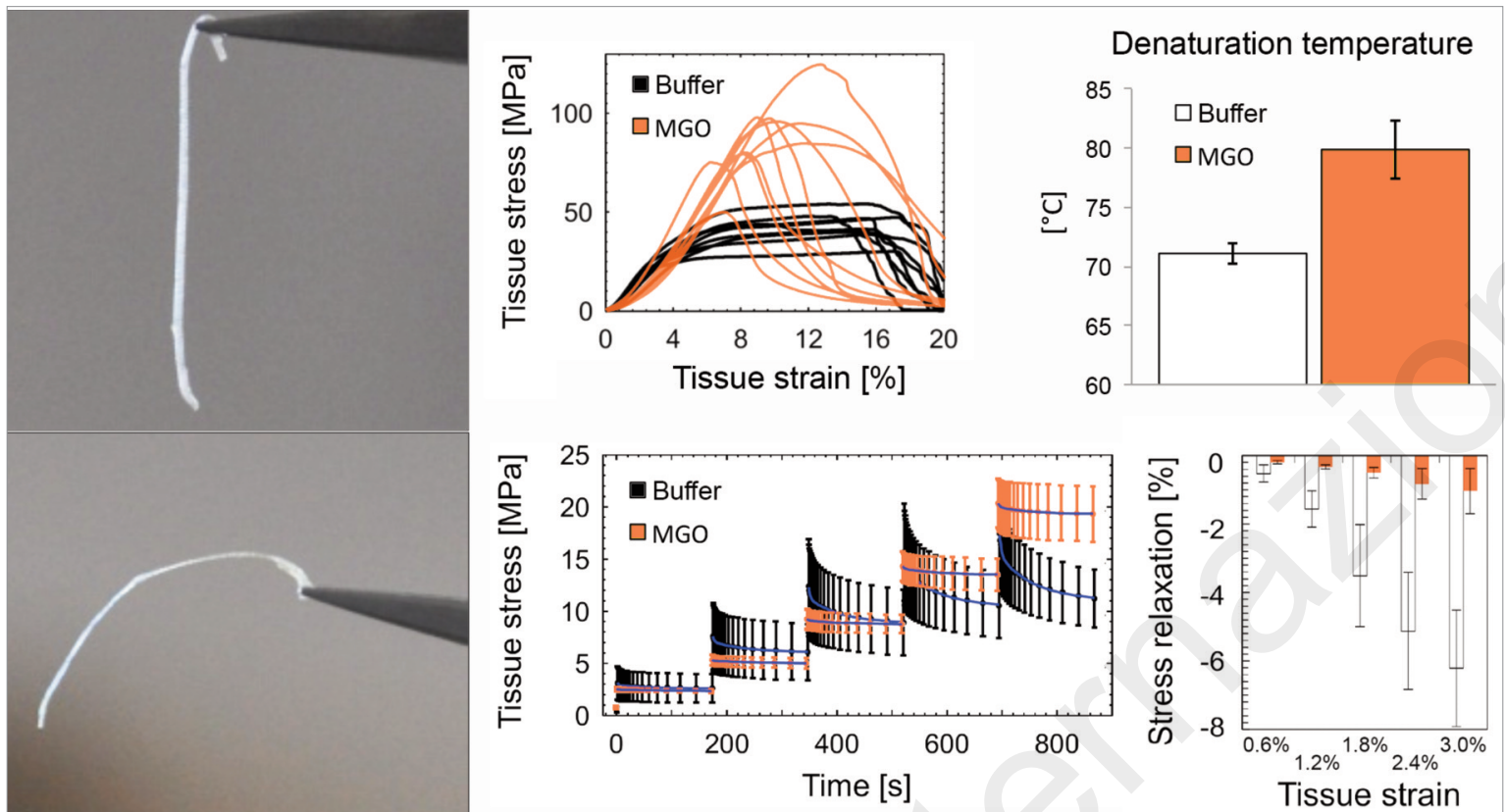

Figure 2. Crosslinking by AGEs induces various physical changes in type-I collagen dominated tissues. In the left-most panels, it can be seen that incubation of rat tail tendon fascicles in high concentrations of metabolite methylglyoxal (MGO) clearly affects tissue mechanics ${ }^{72}$. Closer investigation reveals that while tissue elasticity is only slightly affected, more dominant physical changes are observed in the viscoelastic properties of these tissues, their mode of tensile failure, and their resistance to thermal breakdown. All shown results has been obtained in research conducted ethically according to international standards ${ }^{73}$.

these preventative approaches, some therapeutic approaches have sought to break existing AGE crosslinks. Contrary to the mentioned preventative approaches, crosslink breaking can reverse AGE crosslinking and its deleterious effects on tissue mechanics and matrix remodeling. Since AGE crosslinks in tendon are only secondary complications of diabetes, most anti-AGE work has been done in other tissues (such as skin and arteries). However, their potential effectiveness was first demonstrated using rat tail tendon 60 . At present, the most widely used crosslink breaker is alagebrium (ALT-711) which was shown able to reverse carotid artery stiffness in experimental models of diabetes ${ }^{61}$. However, it is not clear to what extent alagebrium efficacy in reducing diabetes related vascular and myocardial stiffness was due to the breaking of crosslinks. Such effects are also promoted by systemic effects of the drug on cytokine activity and/or oxidative stress reduction ${ }^{62}$. In any case, as far as we are aware there is no study testing the ability of crosslink breaking therapies to ameliorate the predisposition of tendon to mechanical damage, or promote "healthy" tissue remodeling at a repair site.

Another promising strategy for protein deglycation resides in the use of a family of deglycating enzymes $^{35,63,64}$, also called Amadoriases, Fructosyl Amino Acid Oxidases (FAODs) or Fructosyl Amine Oxidases (FAOX). These enzymes, found in fungi and bacteria, are able to cleave low molecular weight Amadori product (i.e., glycated amino acids) and yield the free amine, glucosone and hydrogen peroxide $^{65,66}$. These enzymes have been categorized ${ }^{67}$ into three classes depending on the substrate specificity: (i) active mostly on $\alpha$-fructosyl amino acids (i.e., amino acids glycated on backbone amines), (ii) active mostly on $\varepsilon$-fructosyl amino acids (i.e., amino acids glycated on side-chains amine) and (iii) similar activity on either $\alpha$ - or $\varepsilon$-fructosyl amino acids. The most promising enzymes for protein deglycation are those active on amino acids side chains ( $\varepsilon$-fructosamine), due to the larger number of potential glycation sites. However, despite the fact that from the first isolation of Amadoriase 68 over a dozen similar enzymes have been reported 67 , none has shown significant activity on intact proteins, even after mutagenesis experiments ${ }^{69,70}$. One of the limiting factors in the development of deglycating enzymes with expanded substrate has been the uncertainty on their overall folding and conformation of active site. This limitation has been partly relieved by the finding of the crystal structure of Amadoriase II from Aspergillus fumigatus ${ }^{71}$, possibly paving the way for the development of AGEs treatments.

\section{A Summary}

Collagen crosslinks strongly influence the mechanical and biological function of tendon tissue. While certain types of collagen crosslinks are essential to proper function, others can adversely affect tissue health. In this review, we attempted to distinguish crosslinks 
that promote tissue strength, stiffness, and resistance to failure, from the non-enzymatic crosslinks that are associated with progressive collagen glycation in ageing and diabetes. Concerning the last class of crosslinks, we discussed possible therapeutic strategies to restore healthy tendon matrix mechanics.

\section{Acknowledgements}

This work was enabled by Swiss National Science Foundation grant numbers 205321-118036 (JS) and IZK0Z3-154235 (AG).

\section{References}

1. Chamberlain $P$, Drewello $R$, Korn $L$, et al. Construction of the Khoja Zaynuddin mosque: use of animal glue modified with urine. Archaeometry. 2011;53, 830-841.

2. Fratzl P, Weinkamer R. Nature's hierarchical materials. Progress in Material Science. 2007;52:1263-1334.

3. Fratzl, P. Springer, New York. 2008.

4. Tresoldi I, Oliva F, Benvenuto M, et al. Tendon's ultrastructure. Muscles Ligaments Tendons J. 2013;3:2-6.

5. Di Lullo GA, Sweeney SM, Korkko J, Ala-Kokko L, San Antonio JD. Mapping the ligand-binding sites and disease-associated mutations on the most abundant protein in the human, type I collagen. The Journal of biological chemistry. 2002;277:4223-4231.

6. Craig AS, Birtles MJ, Conway JF, Parry DA. An estimate of the mean length of collagen fibrils in rat tail-tendon as a function of age. Connect Tissue Res. 1989;19:51-62.

7. Bailey AJ. Molecular mechanisms of ageing in connective tissues. Mech Ageing Dev. 2001;122:735-755.

8. Haut RC. The effect of a lathyritic diet on the sensitivity of tendon to strain rate. Journal of biomechanical engineering. 1985;107:166-174.

9. Puxkandl R, et al. Viscoelastic properties of collagen: synchrotron radiation investigations and structural model. Philosophical Transactions of the Royal Society of London Series B-Biological Sciences. 2002;357:191-197.

10. Orgel JP, Wess TJ, Miller A. The in situ conformation and axial location of the intermolecular cross-linked non-helical telopeptides of type I collagen. Structure. 2000; 8:137-142.

11. Eyre DR, Weis MA, Wu JJ. Advances in collagen cross-link analysis. Methods. 2008;45: 65-74.

12. Thorpe CT, Stark RJF, Goodship AE, Birch HL. Mechanical properties of the equine superficial digital flexor. 2010;42:538543.

13. Couppe C, Hansen P, Kongsgaard M, et al. Mechanical properties and collagen cross-linking of the patellar tendon in old and young men. Journal of Applied Physiology. 2009;107:880-886.

14. Birch HL, Wilson AM, Goodship AE. Physical activity: does long-term, high-intensity exercise in horses result in tendon degeneration? Journal of Applied Physiology. 2008;105: 1927-1933.

15. Hansen $P$, Haraldsson BT, Aagaard $P$, et al. Lower strength of the human posterior patellar tendon seems unrelated to mature collagen cross-linking and fibril morphology. J Appl Physiol. 2010;108:47-52.

16. Rigozzi S, Muller R, Snedeker JG. Collagen fibril morphology and mechanical properties of the Achilles tendon in two inbred mouse strains. Journal of anatomy. 2010;216:724-731.

17. Uzel SGM, Buehler MJ. Molecular structure, mechanical behavior and failure mechanism of the C-terminal cross-link do- main in type I collagen. Journal of the Mechanical Behavior of Biomedical Materials. 2011;4:153-161.

18. Mosler E, Folkhard W, Knörzer E, Nemetschek-Gansler H, Th. Nemetschek Th, 18 bis. M.H.J. Koch MHJ. Stress-induced molecular rearrangement in tendon collagen. Journal of molecular biology. 1985;182:589-596.

19. Willett TL, Labow RS, Aldous IG, Avery NC, Lee JM. Changes in collagen with aging maintain molecular stability after overload: evidence from an in vitro tendon model. Journal of biomechanical engineering. 2010;132.

20. Saito M, Marumo K. Collagen cross-links as a determinant of bone quality: a possible explanation for bone fragility in aging, osteoporosis, and diabetes mellitus. Osteoporosis Int. 2010;21:195-214.

21. Bank RA, Bayliss MT, Lafeber FP, Maroudas A, Tekoppele $\mathrm{JM}$. Ageing and zonal variation in post-translational modification of collagen in normal human articular cartilage. The agerelated increase in non-enzymatic glycation affects biomechanical properties of cartilage. Biochem J. 1998;330:345351.

22. Brüel $\mathrm{A}$, Oxlund $\mathrm{H}$. Changes in biomechanical properties, composition of collagen and elastin, and advanced glycation endproducts of the rat aorta in relation to age. Atherosclerosis. 1996;127:155-165

23. Lai-Fook SJ, Hyatt RE. Effects of age on elastic moduli of human lungs. Journal of Applied Physiology. 2000;89:163-168.

24. Sell DR, Lapolla A, Odetti P, Fogarty J, Monnier VM. Pentosidine Formation in Skin Correlates With Severity of Complications in Individuals With Long-Standing IDDM. Diabetes. 1992;41:1286-1292.

25. Haut RC, Lancaster RL, DeCamp CE. Mechanical properties of the canine patellar tendon: some correlations with age and the content of collagen. J Biomech. 1992;25:163-173.

26. Torp S, Arridge R, Armeniades C, Baer E, Friedman B. Structure-property relationships in tendon as a function of age and effects of age and mechanical deformation on the ultrastructure of tendon. Colston Papers. 1974;26:197-249.

27. Avery NC, Bailey AJ. The effects of the Maillard reaction on the physical properties and cell interactions of collagen. Pathologie Biologie. 2006;54:387-395.

28. Avery NC, Bailey AJ. Enzymic and non-enzymic cross-linking mechanisms in relation to turnover of collagen: relevance to aging and exercise. Scand J Med Sci Sports. 2005;15: 231240.

29. Avery NC, Bailey AJ. The effects of the Maillard reaction on the physical properties and cell interactions of collagen. Pathol Biol. 2006;54:387-395.

30. Andreassen TT, Seyerhansen K, Bailey AJ. Thermal-Stability, Mechanical-Properties and Reducible Cross-Links of Rat Tail Tendon in Experimental Diabetes. Biochimica Et Biophysica Acta. 1981;677:313-317.

31. Schnider SL, Kohn RR. Effects of Age and Diabetes-Mellitus on the Solubility of Collagen from Human-Skin, Tracheal Cartilage and Dura Mater. Exp Gerontol. 1982;17:185-194 .

32. Ahmed N. Advanced glycation endproducts-role in pathology of diabetic complications. Diabetes research and clinical practice. 2005;67:3-21.

33. Grandhee SK, Monnier VM. Mechanism of Formation of the Maillard Protein Cross-Link Pentosidine - Glucose, Fructose, and Ascorbate as Pentosidine Precursors. Journal of Biological Chemistry. 1991;266:11649-11653.

34. Sell DR, Biemel KM, Reihl O, Lederer MO, Strauch CM, Monnier VM. Glucosepane is a major protein cross-link of the senescent human extracellular matrix. Relationship with diabetes. The Journal of biological chemistry. 2005;280:1231012315.

35. Monnier VM, Mustata GT, Biemel KL, et al. Cross-linking of the extracellular matrix by the Maillard reaction in aging and dia- 
betes - An update on "a puzzle nearing resolution". Ann Ny Acad Sci. 205;1043:533-544.

36. Bailey AJ, Paul RG, Knott L. Mechanisms of maturation and ageing of collagen. Mechanisms of Ageing and Development. 1998;106:1-56.

37. Bedi A, Fox AJ, Harris PE, et al. Diabetes mellitus impairs tendon-bone healing after rotator cuff repair. Journal of Shoulder and Elbow Surgery. 2010;19:978-988.

38. Frank C, McDonald D, Wilson J, Eyre D, Shrive N. Rabbit medial collateral ligament scar weakness is associated with decreased collagen pyridinoline crosslink density. Journal of Orthopaedic Research. 1995;13:157-165.

39. Gautieri A, Redaelli A, Buehler MJ, Vesentini S. Age- and diabetes-related nonenzymatic crosslinks in collagen fibrils: Candidate amino acids involved in Advanced Glycation End-products. Matrix Biology. 2013.

40. Vesentini S, Redaelli A, Gautieri A. Nanomechanics of collagen microfibrils. Muscles Ligaments Tendons J. 2013;3:23-34.

41. Reigle KL, Di Lullo G, Turner KR, et al. Non-enzymatic glycation of type I collagen diminishes collagen-proteoglycan binding and weakens cell adhesion. J Cell Biochem. 2008;104:16841698.

42. Yan SF, Ramasamy R, Schmidt AM. Mechanisms of Disease: advanced glycation end-products and their receptor in inflammation and diabetes complications. Nat Rev Endocrinol. 2008;4:285-293.

43. Galeski A, Kastelic J, Baer E, Kohn RR. Mechanical and structural changes in rat tail tendon induced by alloxan diabetes and aging. Journal of Biomechanics. 1977;10:775-782.

44. Fox AJ, Bedi A, Deng XH, et al. Diabetes mellitus alters the mechanical properties of the native tendon in an experimental rat model. Journal of Orthopaedic Research. 2011;29: 880885.

45. Reddy GK, Stehno-Bittel L, Enwemeka CS. Glycation-induced matrix stability in the rabbit Achilles tendon. Archives of Biochemistry and Biophysics. 2002;399:174-180.

46. Reddy GK. Cross-linking in collagen by nonenzymatic glycation increases the matrix stiffness in rabbit Achilles tendon. Experimental Diabesity Research. 2004;5:143-153.

47. de Oliveira RR, de Lira KD, Silveira PV, et al. Mechanical Properties of Achilles Tendon in Rats Induced to Experimental Diabetes. Annals of Biomedical Engineering. 2011;1-7.

48. Lancaster RL, Haut RC, DeCamp CE. Changes in the mechanical properties of patellar tendon preparations of spontaneously diabetic dogs under long-term insulin therapy. J Biomech. 1994;27:1105-1108.

49. Goh KL, Holmes DF, Lu HY, et al. Ageing changes in the tensile properties of tendons: influence of collagen fibril volume fraction. Journal of biomechanical engineering. 2008;130.

50. Dressler MR, Butler DL, Wenstrup R, Awad HA, Smith F, Boivin GP. A potential mechanism for age-related declines in patellar tendon biomechanics. Journal of Orthopaedic Research. 2002;20:1315-1322.

51. Blevins FT, Hecker AT, Bigler GT, Boland AL, Hayes WC. The Effects of Donor Age and Strain Rate on the Biomechanical Properties of Bone-Patellar Tendon-Bone Allografts. The American Journal of Sports Medicine. 1994;22:328-333.

52. Lewis G, Shaw KM. Tensile properties of human tendo achillis: Effect of donor age and strain rate. The Journal of Foot and Ankle Surgery. 1997;36:435-445.

53. Kent MJ, Light ND, Bailey AJ. Evidence for glucose-mediated covalent cross-linking of collagen after glycosylation in vitro. Biochem J. 1985;225:745-752.

54. Bai PM, Phua K, Hardt T, Cernadas M, Brodsky B. Glycation alters collagen fibril organization. Connect Tissue Res. 1992;28:1-12.

55. Singh R, Barden A, Mori T, Beilin L. Advanced glycation endproducts: a review. Diabetologia. 2001;44:129-146.

56. Goldin A, Beckman JA, Schmidt AM, Creager MA. Advanced Glycation End Products: Sparking the Development of Diabetic Vascular Injury. Circulation. 2006;114:597-605.

57. Sell DR, Monnier VM. Molecular basis of arterial stiffening: role of glycation - a mini-review. Gerontology. 2012;58:227-237.

58. Monnier VM, Mustata GT, Biemel KL, et al. Cross-Linking of the Extracellular Matrix by the Maillard Reaction in Aging and Diabetes: An Update on "a Puzzle Nearing Resolution". Annals of the New York Academy of Sciences. 2005;1043:533544.

59. Sjoberg JS, Bulterijs S. Characteristics, formation, and pathophysiology of glucosepane: a major protein cross-link. Rejuvenation Res. 2009;12:137-148.

60. Vasan S, Zhang X, Zhang X, et al. An agent cleaving glucosederived protein crosslinks in vitro and in vivo. Nature. 1996;382:275-278.

61. Wolffenbuttel BH, Boulanger CM, Crijns FR, et al. Breakers of advanced glycation end products restore large artery properties in experimental diabetes. Proceedings of the National Academy of Sciences. 1998;95:4630-4634.

62. Susic D. Cross-link breakers as a new therapeutic approach to cardiovascular disease. Biochem Soc Trans. 2007;35:853856.

63. Monnier VM, Wu X. Enzymatic deglycation with amadoriase enzymes from Aspergillus sp. as a potential strategy against the complications of diabetes and aging. Biochem Soc Trans. 2003;31:1349-1353.

64. Wu X, Monnier VM. Enzymatic deglycation of proteins. Arch Biochem Biophys. 2003;419: 16-24.

65. Mennella C, Borrelli RC, Vinale F, Ruocco M, Fogliano V. Substrate specificity of amadoriase I from Aspergillus fumigatus. Ann Ny Acad Sci. 2005;1043:837-844.

66. Capuano E, Fedele F, Mennella C, et al. Studies on the effect of amadoriase from Aspergillus fumigatus on peptide and protein glycation in vitro. J Agr Food Chem. 2007;55:4189-4195.

67. Lin ZL, Zheng J. Occurrence, characteristics, and applications of fructosyl amine oxidases (amadoriases). Appl Microbiol Biot. 2010;86:1613-1619.

68. Takahashi M, Pischetsrieder M, Monnier VM. Isolation, purification, and characterization of amadoriase isoenzymes (fructosyl amine-oxygen oxidoreductase EC 1.5.3) from Aspergillus sp. Journal of Biological Chemistry. 1997;272:34373443.

69. Zheng J, Guan H, Xu LH, Yang R, Lin ZL. Engineered amadoriase II exhibiting expanded substrate range. Appl Microbiol Biot. 2010;86:607-613.

70. Qian Y, Zheng J, Lin ZL. Loop engineering of amadoriase II and mutational cooperativity. Appl Microbiol Biot. 2013;97:85998607.

71. Collard F, Zhang J, Nemet I, Qanungo KR, Monnier VM, Yee VC. Crystal structure of the deglycating enzyme fructosamine oxidase (amadoriase II). The Journal of biological chemistry. 2008;283:27007-27016.

72. Li Y, Fessel G, Georgiadis M, Snedeker JG. Advanced glycation end-products diminish tendon collagen fiber sliding. Matrix biology: journal of the International Society for Matrix Biology. 2013;32:169-177.

73. Padulo J, Oliva F, Frizziero A, Maffulli N. Muscles, Ligaments and Tendons Journal. Basic principles and recommendations in clinical and field science research. MLTJ. 2013;4: 250-252. 